\title{
Predicting the Effect of Gearbox Preconditioning on Vehicle Efficiency
}

\author{
R. Gillot* A. Picarelli* M. Dempsey* \\ *Claytex Services Ltd. Edmund House, Rugby Road, Leamington Spa, CV32 6EL \\ \{romain.gillot, alessandro.picarelli, mike.dempsey\} @claytex.com
}

\begin{abstract}
Under extreme climatic conditions, the vehicle fuel consumption can be far from the certified value. Given the growing concern for polluting emissions, it is necessary to investigate a way to improve the overall vehicle efficiency and thus reduce the emissions and fuel consumption gap. One solution is to pre-warm the gearbox in order to make it work at an optimal temperature to achieve the best efficiency possible. Indeed, low lubricant temperature is a source of reduced vehicle efficiency due to the lubricant viscosity rising exponentially at very low temperature.

Using the Powertrain Dynamics library, a vehicle model with a detailed equation based gearbox model taking into account the temperature-dependent losses is developed.
\end{abstract}

Keywords: gearbox, pre-warming, efficiency, fuel consumption, oil temperature

\section{Introduction}

Responding to the ever growing need to reduce vehicle fuel consumption and pollutant emissions, new technologies have been developed and successfully implemented in a large number of vehicles over the last few years. However, if engine efficiency has recently dramatically increased thanks to ongoing design improvements and new technologies, the question is how much further we can push the limits to improve efficiency in use and at what price.

One way to achieve better performance from the powertrain is to improve its efficiency. To do so, we have to keep in mind that our vehicles are rarely operated in their optimal efficiency region due mainly to the road layouts, road traffic, driver behaviour, short range operation and the climatic conditions. We can at least seek to counteract the effects of the latter on vehicle efficiency. Vehicle transmission oil viscosity increases exponentially at low temperatures, affecting the vehicle transmission efficiency. Until the oil has fully warmed-up, which can take a rather long time under extreme cold weather conditions, the transmission losses are very high due to drag on the gears, clutches and bearings caused by the viscous oil. Poor range and fuel economy can result in customer dissatisfaction compounded by the fact that the vehicle is only being used exploiting a small percentage of its certified power. The idea is then to put the transmission (and in future other subsystems such as engine and traction battery as part of a larger study) in the best conditions whatever the weather is in order to increase its efficiency. Farrant et al. showed the benefits of powertrain preconditioning during a cold start (Farrant P.E. et al. (2005).

In this paper we build a vehicle model in Dymola using components from the Powertrain Dynamics Library. We then precondition the transmission lubricant to several temperatures and run the vehicle model over the standard NEDC and ARTEMIS drive cycles. The ARTEMIS drive cycle combines an urban and a highway portion. The models involved in this study are predictive equation based models in order to show how the efficiency would benefit from higher oil temperatures without the constraints of map/empirical based models. The benefits of preconditioning are then highlighted as well as the costs of doing so.

\section{The Vehicle Model}

The vehicle includes a predictive thermal model of the transmission to quantify the thermal dynamics of the system including losses such as bearing and gear drag losses. The heat release from friction is evaluated in each area of the model. All gearbox components (moving and non-moving) are interlinked via mechanical and/or thermal ports so that the effects of each component in the system on the others can be evaluated. This physical relationship modelling forms the basis for predicting the oil temperature and viscosity in the whole subsystem.

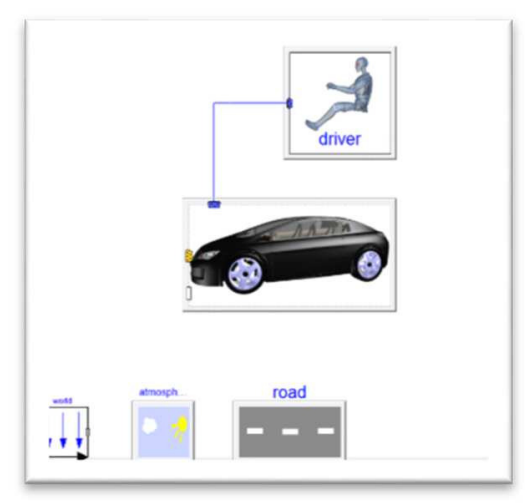

Figure 1. Vehicle model experiment complete with driver model, road and atmosphere (environment) models

The vehicle model is built on the VehicleInterfaces library standard from Modelica Association. All models use Multibody components and are designed for easy assembly and efficient computation (Dempsey M. et al. 2009). A Driver 


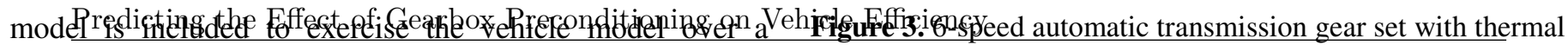
specific drive cycle in order to evaluate its efficiency and performance. A road model and an atmosphere model are also used in the experiment and interface with the vehicle model.

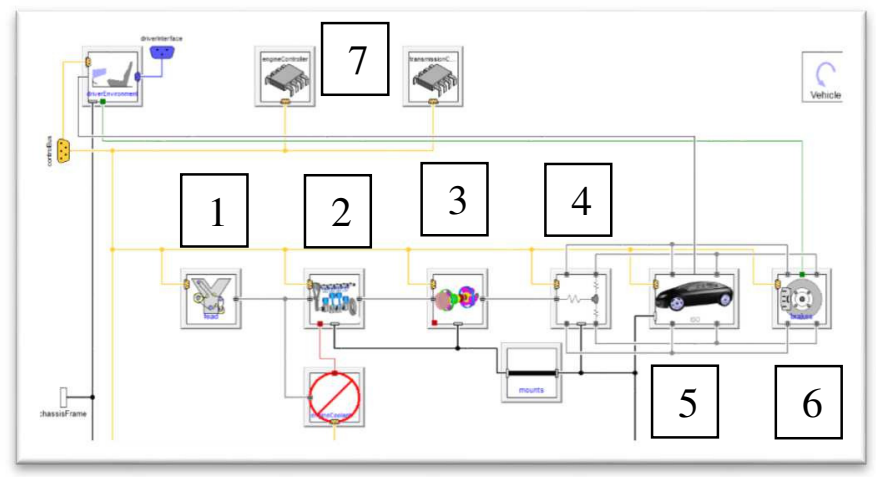

Figure 2. Detailed view of the vehicle model with all the subsystems:1-Ancillaries, 2-Engine, 3-Gearbox, 4-driveline, 5Chassis, 6-Brakes, 7-Controllers

The model above (Figure 2) is a view of the vehicle one level lower than the previous one (Figure 1).

The main subsystems are: Engine, Transmission, Driveline and Chassis.

The engine model uses a performance map giving an output torque depending on pedal position and engine speed. A fuel tank is included to enable the calculation of the instantaneous and average fuel consumptions. The engine used in this experiment is a two-litre four-cylinder petrol engine.

The transmission model will be discussed in detail in the next section.

The driveline model can be set to include compliance, stiffness and damping characteristics so that the same vehicle can also be used for detailed driveability studies.

The chassis model has a pitch degree of freedom and longitudinal motion as well as models for tyres, aerodynamics and suspension.

\section{The Transmission Model}

\subsection{Overview}

In this study focus is on a six-speed automatic transmission which includes a dynamic torque converter model with predictive thermal effects, gear sets with bearing friction and bearing drag models, gear mesh models with temperaturedependent efficiency, a shift actuation system and a heat port (thermal connector) to port the generated heat to other vehicle subsystems.

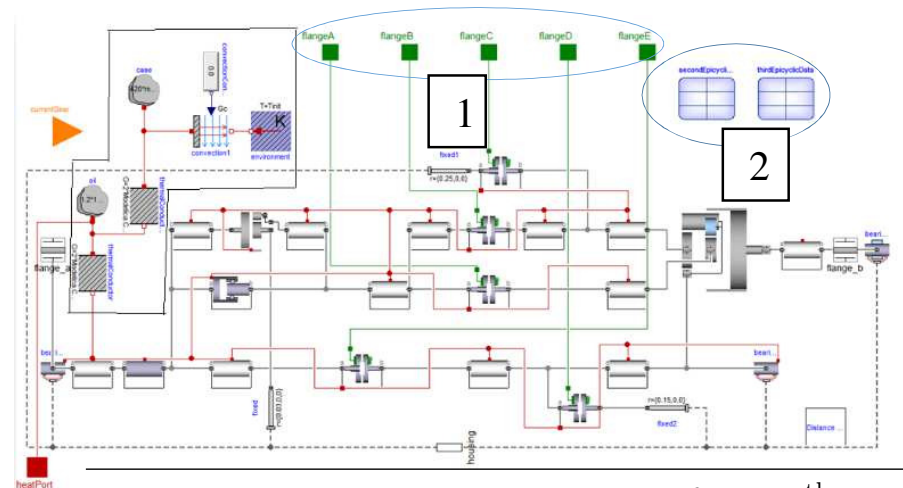




$$
\begin{aligned}
p_{L}=\frac{\rho}{2} \operatorname{sgn}(Q) & \left(C_{s h, i} V_{s h, i}^{2}+C_{s h, t} V_{s h, t}^{2}+C_{s h, s} V_{s h, s}^{2}\right) \\
+ & \frac{\rho f}{2} \operatorname{sgn}(Q)\left(V_{i}^{* 2}+V_{t}^{* 2}+V_{s}^{* 2}\right)
\end{aligned}
$$

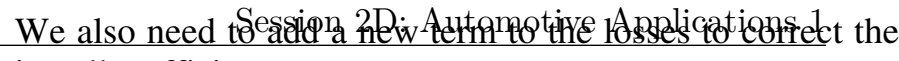
impeller efficiency:

$$
p_{L 2}=\frac{\tau_{t} \omega_{t}\left(C_{n}-1\right)}{Q}
$$

Where $C_{s h, i}$ is the shock loss coefficient for the impeller and $V_{s h, i}^{2}$ is the shock velocity. $\mathrm{f}$ is a fluid friction factor and $V_{i}^{* 2}$ is the fluid velocity relative to blades.

We know the fluid viscosity significantly affects the torque converter efficiency, this is why we need to include the thermal effects in the model.

A formula in (Hydraulic Institute, 2010) gives a performance factor (B) in order to calculate a correction factor to reevaluate the impeller efficiency when using a viscous fluid.

$$
B=K\left[\frac{V_{v i S}{ }^{0.5} H_{B E P-W}{ }^{0.0625}}{Q_{B E P-H}{ }^{0.375} N^{0.25}}\right]
$$

Where $\mathrm{V}$ is the fluid viscosity, $\mathrm{H}$ is the impeller head, Q is the fluid flow rate and $\mathrm{N}$ is the impeller shaft speed. We can now use this performance parameter to determine the correction factors $C_{H}$ for the head, $C_{q}$ for the volume flow rate and $C_{n}$ for the efficiency.
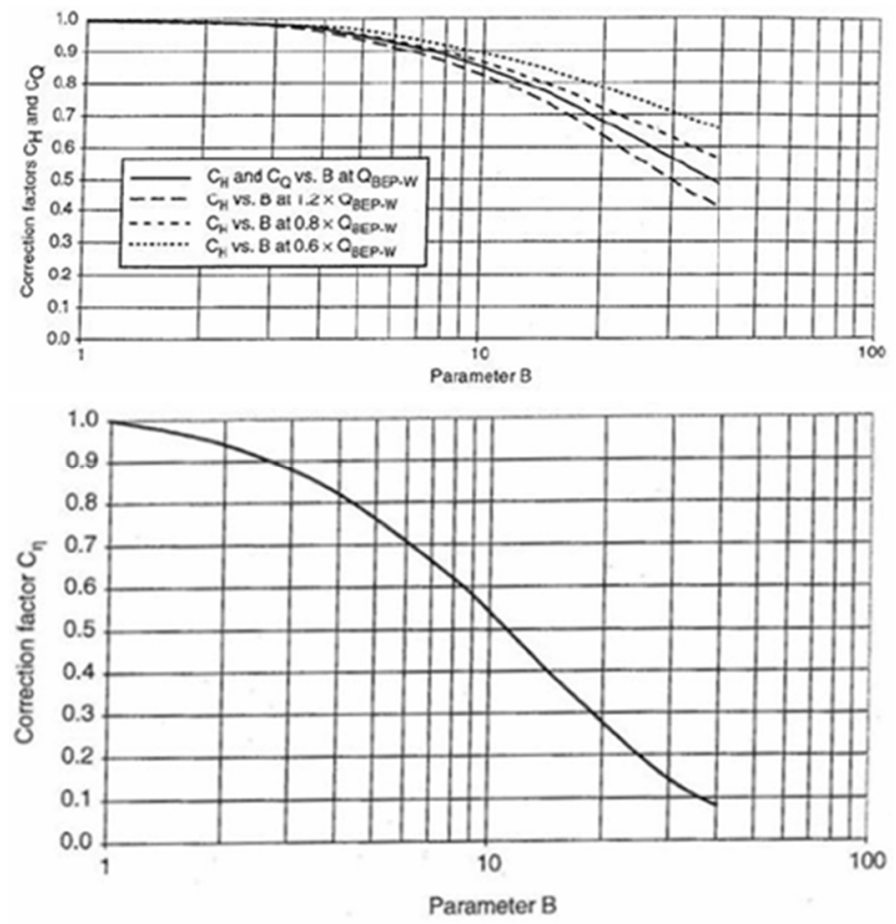

Figure 4. Correction factors $C_{H}, C_{Q}$ and $C_{n}$ plotted against the performance factor $B$.

These correction factors allow us to modify the losses to account for the thermal effects.

First we introduce the volume flow's corrected value:

$p_{L, \text { thermal effects }}$

$$
\begin{aligned}
& =\frac{\rho}{2} \operatorname{sgn}(Q)\left(C_{s h, i} V_{s h, i}^{2}+C_{s h, t} V_{s h, t}^{2}\right. \\
& \left.+C_{s h, s} V_{s h, s}^{2}\right) \\
& +\frac{\rho f}{2} \operatorname{sgn}(Q)\left(\frac{V_{i}^{* 2}+V_{t}^{* 2}+V_{s}^{* 2}}{C_{q}^{2}}\right)
\end{aligned}
$$

These corrections result in the turbine rotational speed to converge more slowly towards the impeller angular velocity as can be seen in Figure 5 .

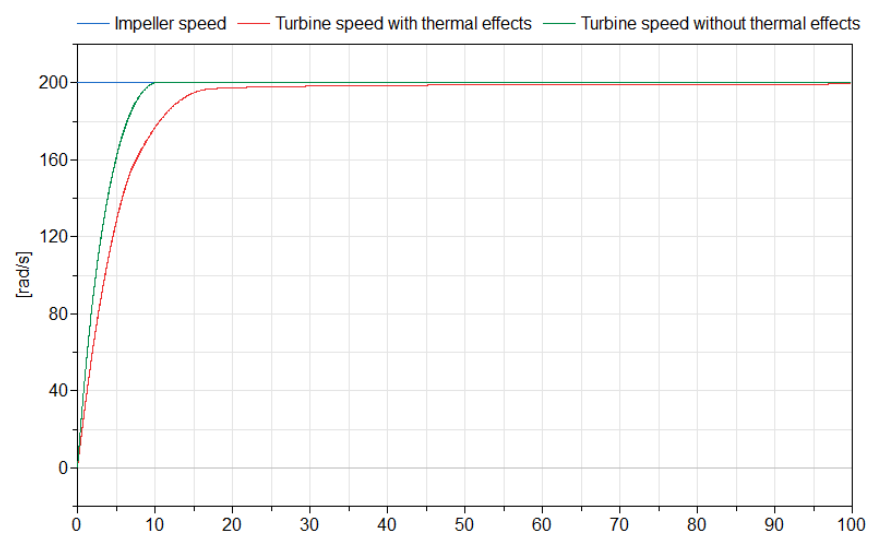

Figure 5. Impeller and turbine speeds vs. time [s] with and without taking into account the thermal effects.

When the oil is cold and has a high viscosity the flow's axial velocity inside the torque converter is reduced and so the fluid inertia transmitted to the turbine is not as good and it takes longer to reach the coupling point. The overall torque converter efficiency is then affected.

\subsection{Roller bearings}

The roller bearings are important components as they can achieve very good efficiencies under appropriate conditions. However, when the oil viscosity is high their efficiency dramatically drops. Since all the components in the transmission model are thermally linked, the heat released by other parts of the model (clutches, torque converter, etc.) can affect the bearing behaviour through warming up of the transmission fluid and gradually help to improve the overall system efficiency.

The bearing friction torque is given by:

$$
T_{\text {friction }}=f n * \operatorname{coeff} * R+T_{\text {seals }}+T_{\text {drag }}
$$

The friction coefficient coeff depends on the type of rollers (ball, pin, taper pin, etc.) and typically varies between 0.001 and 0.0024 .

The friction torque due to the seals is not detailed here as it has only a small contribution and does not vary significantly with temperature. 
Predicting the Effect of Gearbox Preconditioning on Vehicheriff(qigmey. $\mathrm{h}$ is the oil film thickness which reduced under

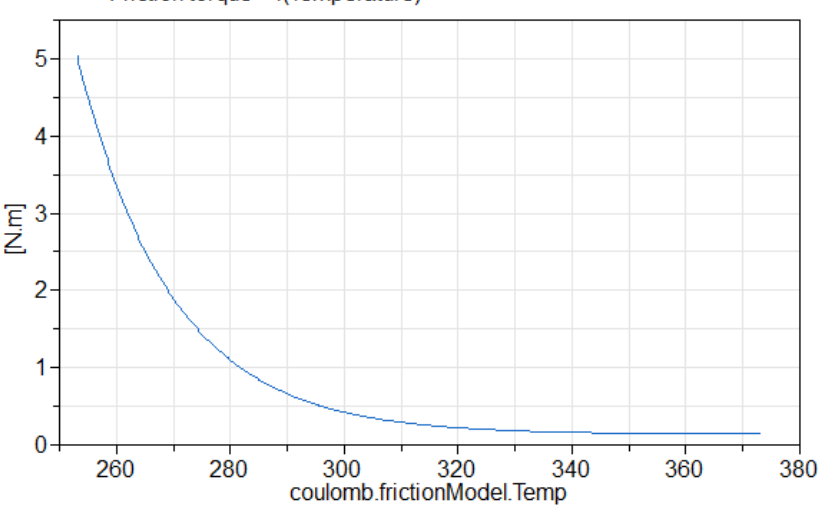

Figure 6: Friction torque of a roller bearing depending on the oil temperature

The drag torque formula (SKF website) demonstrates the importance of the oil viscosity:

$$
\begin{gathered}
T_{\text {drag }}=4 * V_{m} * K_{\text {roll }} * C_{\omega} * B * d_{m}{ }^{4} * n^{2} \\
+1.093 \times 10^{-7} * n^{2} * d_{m}{ }^{3} *\left(\frac{n * d_{m}{ }^{2} * f_{t}}{v}\right)^{-1.379} * R_{s}
\end{gathered}
$$

$\mathrm{v}$ is the kinematic viscosity at operating temperature.

$C_{\omega}$ and $K_{\text {roll }}$ depend on the bearing geometry and dimensions.

$V_{m}$ is the drag loss factor.

$R_{S}$ is calculated with the bearing dimensions and the oil level (see picture below).

$\mathrm{n}$ is the bearing rotational speed.

$f_{t}$ depends on the bearing geometry and the oil level.

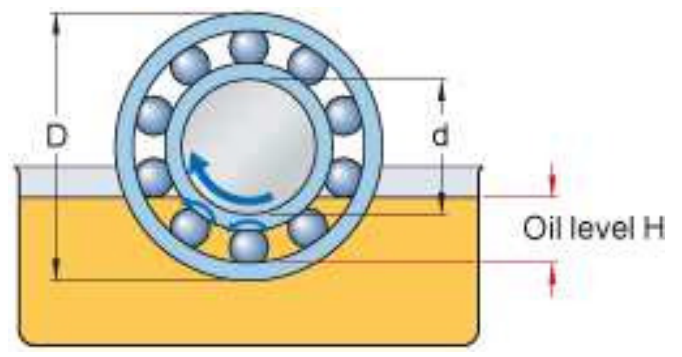

The oil level is the distance above the lowest contact point between the rolling element and the outer ring.

\subsection{Clutches}

There are several clutches utilised throughout the transmission model. There is a lock-up clutch in the torque converter model and three other clutches are used in the gear set along with two brakes which use the same type of model. Clutches are modelled by multiple rotating plates pressed together via a normal force (via the green flange in the next picture).

The friction torque between the clutch plates is calculated as follows:

$$
T_{\text {friction }}=\mu * N_{f} *\left(\varphi_{f}+\varphi_{s}\right) * \frac{\pi * w_{r e l} *\left(r_{o}^{4}-r_{i}^{4}\right)}{2 h}
$$

where $\mu$ is the oil viscosity, $\varphi_{f}$ and $\varphi_{s}$ are the pressure and shear stress flow factors respectively, introduced by Patir and applied pressure (Dempsey M. et al. 2012). $N_{f}$ is the number of friction plates.

The heat generated by the friction between the clutch plates is expelled through the heat port and stored into a heat capacitor which is linked to further thermal models in the system. The heat capacitor accounts for the thermal mass of driven and driving plates. The temperature of the clutch plates can thus be evaluated as well as the thermal losses to the clutch surroundings.

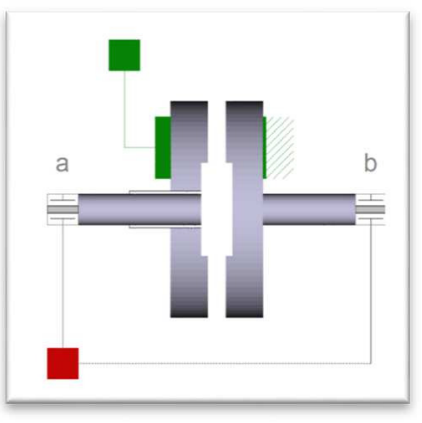

Figure 7. Clutch model with heat port (red) and mechanical actuation flange (green)

During slipping, clutches and brakes can generate considerable amounts of heat in the gearbox which contributes to lower the oil viscosity thus affecting the whole transmission efficiency. However, the friction torque is only significant for a small amount of time.
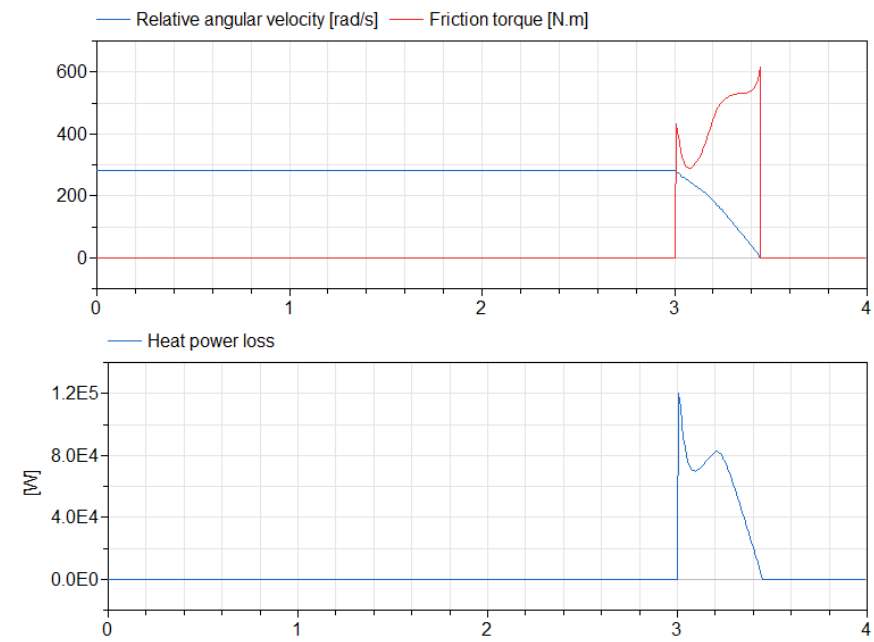

Figure 8. Friction torque and relative angular speed (top) and heat power loss (bottom) vs. time [s] 


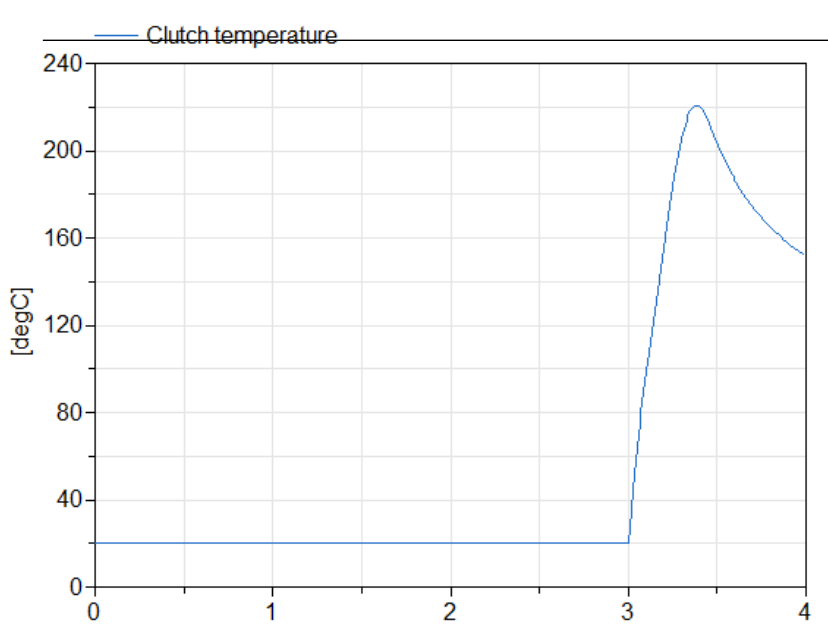

Figure 9. Evolution of the temperature at the clutch plates vs. time $[s]$

During operation, the clutch temperature can rise very quickly. We can see on the graph above (Figure 8) that heat is released when both the relative angular velocity and the torque transmitted are non-zero which essentially happens during the engagement and disengagement phase.

\subsection{Gears}

We can divide the gear losses into speed-dependent and loaddependent losses. Speed-dependent losses consist of windage losses and oil churning losses. Load-dependent losses consist of sliding friction losses and rolling friction losses.

The windage losses are induced by oil droplets that are in suspension in the gearbox housing and create a thin mist which increases the gear frictional resistance.

The churning losses are due to the oil being trapped in the gear mesh and to the gear rotating in the lubricant. They depend on the gear rotational speed, the oil viscosity, the gear geometry and the proportion of the gear submerged.

The sliding and rolling friction losses are dependent on the gear rotational speed and on the instantaneous coefficient of friction.

We are mostly interested in the churning losses since they are closely related to the oil properties.

The churning losses for tooth surface are given by (Heingartner P., Mba D., 2003):

$$
P_{C l}=\frac{7.37 f_{g i} * \mu * n_{i}^{3} * D_{i}^{4.7} * b_{i} *\left(\frac{R_{f}}{\sqrt{\tan \beta}}\right)}{A_{g} 10^{23}}
$$

$f_{g i}$ is the gear dip factor that is to say the ratio of the gear dipping into oil. $\mathrm{D}$ is the outside diameter, $\beta$ is the helix angle and $R_{f}$ is the roughness factor.

The oil viscosity $\mu$ plays a major role in the amount of churning losses and thus we can easily see the importance of the temperature on these. $\mathrm{n}$ is the gear rotational speed and all the other parameters in the formula are geometrical dimensions.

Two other similar formulae exist to calculate the churning losses for smooth outside diameters and smooth sides of discs (i.e. shafts and gear side faces respectively).
Session 2D: Automotive Applications 1

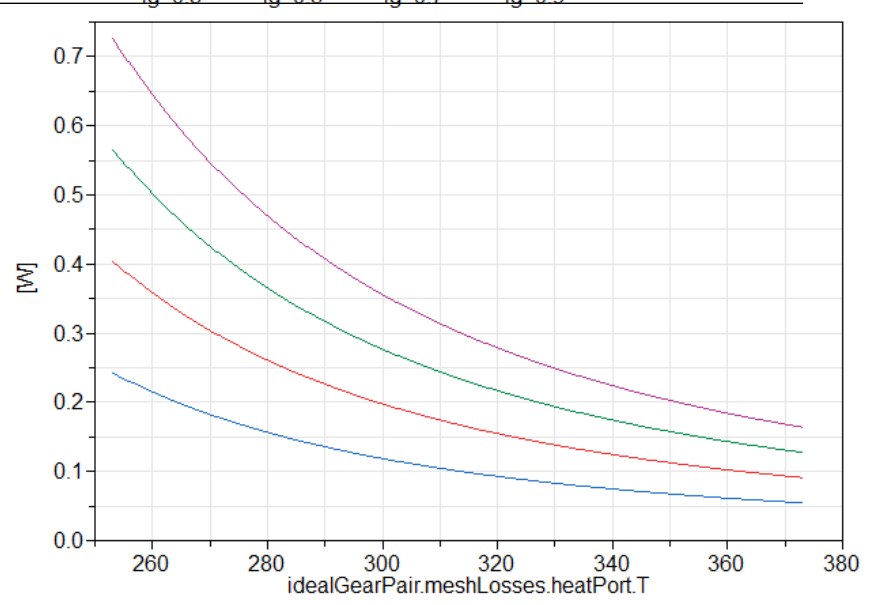

Figure 10: Example of oil churning losses with respect to oil temperature with different dip factors.

The churning losses increase at low temperatures and this is even a bigger difference when the dip factor is high as a larger part of the gear is dragged through oil.

\section{Results}

Prior to the calculation of vehicle fuel economy, a quick estimation of the cost to per-warm the gearbox can be made. If we apply a heat flow of 100 Watts, it takes 886 seconds to heat the gearbox from $-10 \operatorname{deg} C$ up to $+90 \operatorname{degC}$. At an average price at the time of the study (in England) was $£ 0.15$ per $\mathrm{kWh}$, the electricity needed will cost $£ 0.0037$. Even if the objective here is not to make money out of this solution, the cost has to be evaluated and the results clearly shows that it should not be a financial problem for the customer. This type of preconditioning is more suited in vehicles such as plug-in hybrids or EVs (Electric Vehicles) or indeed conventional vehicles operating in cold climates where the customer might, by default, plug the vehicle in to recharge the battery and/or precondition the cabin.

\subsection{NEDC}

The NEDC Cycle is used to homologate vehicles including Euro 6 standard. It is made up from an urban section repeated four times and an extra-urban section. It covers a distance of 11023 meters and lasts for 1180 seconds. It is often criticised for not representing real-life driving conditions (too light duty). However it has to be considered as it is used for homologation but also because we are interested in slow urban driving conditions to attest the maximum savings possible (slower gearbox warm-up).

\section{DOI}

10.3384/ecp15118135 


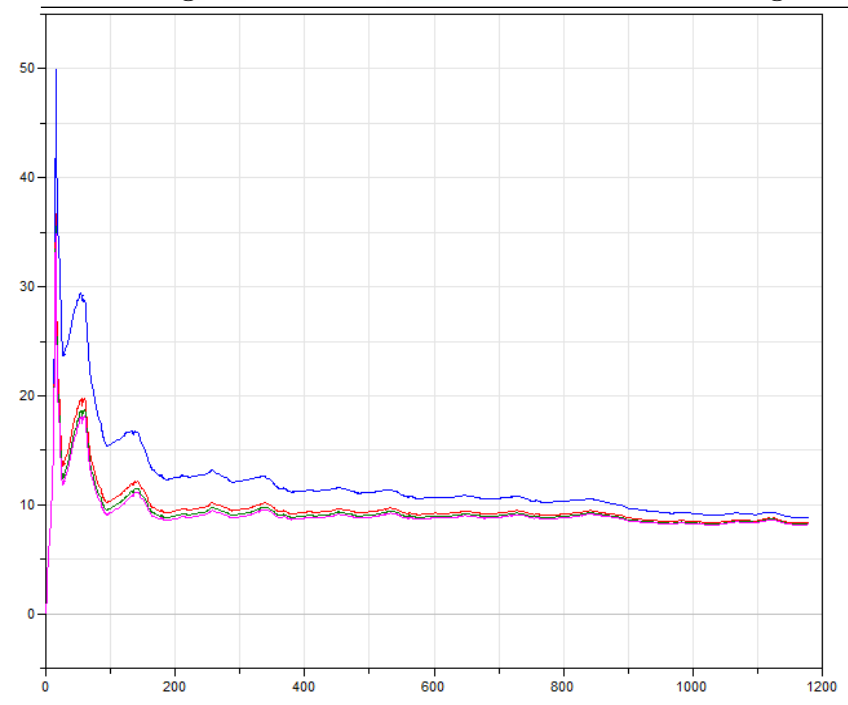

Figure 11. Average fuel consumption NEDC $(1 / 100 \mathrm{~km})$ under different start temperatures: -10deg (blue), +23deg (red), +40deg (green), +90deg (magenta) vs. time [s]

We can see that the greatest saving occurs at the beginning of the cycle, in the urban portion at low load. While the oil temperature reaches its ideal value, the average fuel consumption with a pre-warmed gearbox converges towards the average fuel consumption with a non-pre-warmed gearbox.

If the ambient temperature is $+23 \mathrm{degC}$, pre-warming the transmission fluid to $+90 \operatorname{degC}$ allows a fuel economy improvement of $1.71 \%(150 \mathrm{~mL})$.

If the ambient temperature is now $-10 \mathrm{degC}$, pre-warming the transmission fluid to $+90 \mathrm{degC}$ yields a fuel economy benefit of $7.66 \%(660 \mathrm{~mL})$.

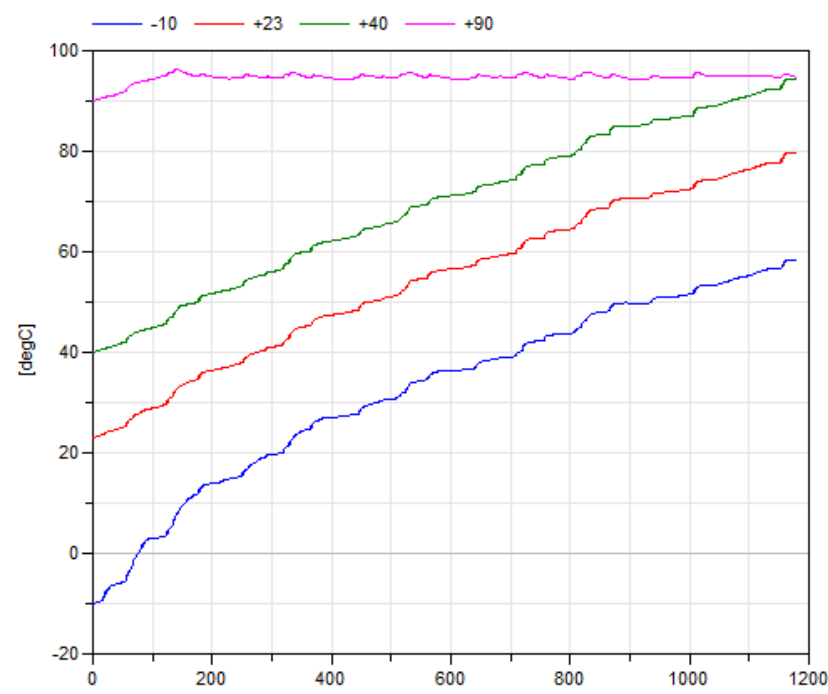

Figure 12. Oil temperature with different start values: -10deg (blue), +23deg (red), +40deg (green), +90deg (magenta) vs. time $[\mathrm{s}]$

The oil temperature reaches its ideal value when starting at $40 \mathrm{degC}$ only towards the end of the drive cycle while the others do not even come close, this explains the significant fuel savings.
The ARTEMIS drive cycle is based on a statistical study and thus fits better to the real usage of the vehicles. It is made of an urban part and a highway portion. It covers a distance of 33605 meters and lasts for 2061 seconds. In comparison with the NEDC drive cycle, ARTEMIS is much more aggressive.

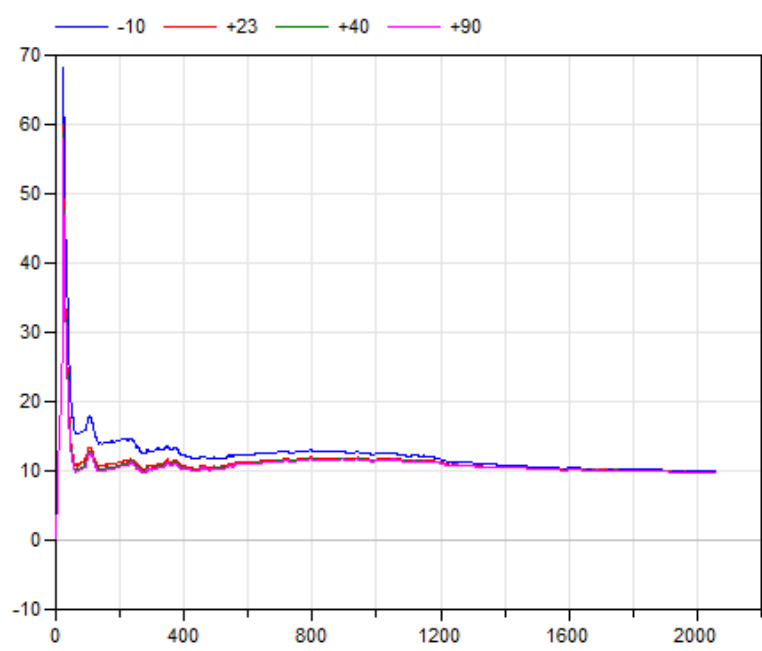

Figure 13. Average fuel consumption ARTEMIS $(1 / 100 \mathrm{~km})$ under different start temperatures: -10deg (blue), +23deg (red), +40deg (green), +90deg (magenta) vs. time [s]

The potential fuel economy benefit from pre-warming the transmission is less obvious on this cycle. Indeed, as it is more aggressive, the components take less time to heat-up and so the benefit in pre-warming disappears more rapidly.

If the ambient temperature is $+23 \mathrm{degC}$, pre-warming the transmission fluid to $+90 \operatorname{degC}$ yields a fuel economy improvement of $0.24 \%(37 \mathrm{~mL})$.

If the ambient temperature is now $-10 \mathrm{degC}$, pre-warming the transmission fluid to $+90 \mathrm{degC}$ yields a fuel economy benefit of $1.84 \%(182 \mathrm{~mL})$.

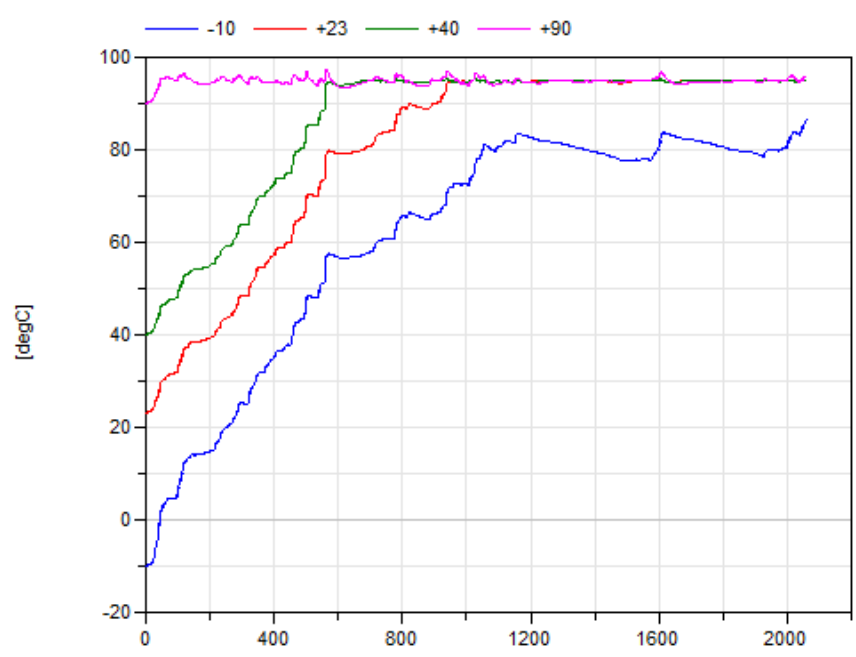

Figure 14. Oil temperature with different start values: -10deg (blue), +23deg (red), +40deg (green), +90deg (magenta) vs. time [s]

This graph (Figure 14) shows that the oil takes less time to reach its ideal value with the ARTEMIS drive cycle than with 
the NDEC drive cycle. This is due to the ARTEMIS cycle being more aggressive.

An interesting occurrence that can be noticed in both drive cycles is that the overall vehicle efficiency does not increase much after the oil reaches $+23 \operatorname{degC}$. The fuel economy when submitted to an initial temperature of $+90 \mathrm{degC}$ instead of $+23 \operatorname{degC}$ is only $1.71 \%$ for the NEDC cycle and $0.24 \%$ for the ARTEMIS cycle. This tells us that we could consider preconditioning the gearbox to only $+23 \operatorname{degC}$ as the benefits after this value are much less worth the cost.

\subsection{Applied Example}

Let's consider a real-life example to give us a concrete idea of the potential savings that could be achieved at a larger scale.

In Göteborg, Sweden (1 million people live in its urban area):

- 100000 people commute to work every day

- 60000 people commute by car every day

- $12 \mathrm{~km}$ (7.5 miles) / 24 minutes is the average commute ride inside Göteborg

- $51 \mathrm{~km}$ (31.7 miles) /50 minutes is the average commute ride outside Göteborg

If we make the assumption of 50000 commuting trips per day, it gives us a saving a 25000 litres of fuel and 62 tons of $\mathrm{CO}_{2}$ per day.

\section{Conclusions}

The benefits of gearbox preconditioning have been studied and show that this strategy could be a real possibility in the future. A device to pre-warm the gearbox and the way for the customers to choose when to use it have still to be explored though.

As the differences in the results between the NEDC and ARTEMIS drive cycles showed us, the best potential savings could be achieved in a busy urban environment where the transmission fluid would usually take a long time to reach its ideal working temperature.

Pre-warming of other subsystems like traction batteries would allow even greater fuel economy and performance benefits and will be considered in further work. In the case of electric vehicles it is even a necessity to heat up the battery in extremely cold climates due to the performance degradation of the battery at very low temperatures. It has been shown (Tikhonov K., Koch V.R) that the battery discharge can reach $60 \%$ when the air temperature drops from $22{ }^{\circ} \mathrm{C}\left(72{ }^{\circ} \mathrm{F}\right)$ to $-40{ }^{\circ} \mathrm{C}\left(-40{ }^{\circ} \mathrm{F}\right)$. To the evident issue when driving more than a couple of hours adds up the bad perception of the user if the engine can only deliver half of the 100bhp at cold start.

\section{References}

Dempsey M. et al. (2009) Investigating the Multibody Dynamics of the Complete Powertrain System, Como, Italy, Proceedings of the $7^{\text {th }}$ Modelica Conference

Dempsey M. et al. (2006) Coordinated automotive libraries for vehicle system modelling, Vienna, Austria, Proceedings of the 5th International Modelica Conference

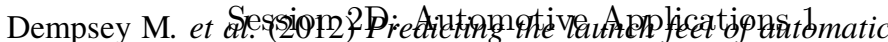
and dual clutch transmissions, Munich, Germany, Proceedings of the $9^{\text {th }}$ International Modelica Conference

Farrant P.E. et al. (2005) The Application of Thermal Modelling to an Engine and Transmission to Improve Fuel Consumption Following a Cold Start, Toronto, Canada, Vehicle Thermal Management Systems Conference and Exhibition.

Heingartner P., Mba D., (2003) Determining power losses in the helical gear mesh, Chicago, United States, International Power Transmission and Gearing Conference.

Hydraulic Institute, (2010) Effects of liquid viscosity on rotodynamic (centrifugal and vertical) pump performance.

Jandasek V.J., (1994) Design of Single-stage, Three-element Torque Converter, Design Practice: Passenger Car Automatic Transmissions, Third Edition, AE-18, SAE, pp.75 102

Shin S., Bae I. et al, (2000) The Effect of Blade Geometry on the Performance of an Automotive Torque Converter, FISITA World Automotive Congress, Seoul, Korea

SKF website: http://www.skf.com/group/products/bearings-unitshousings/ball-bearings/principles/friction/skf-model/draglosses/drag-losses-in-oil-bath/index.html

Tikhonov K., Koch V.R., Li-ion Battery Electrolytes Designed For a Wide Temperature Range, Covalent Associates, Inc. 